\title{
A case of intussusception developed at the site of ileocolic anastomosis after laparoscopic right hemicolectomy
}

\author{
Tamuro Hayama1*, Yojiro Hashiguchi', Kohei Ohno', Yuka Okada', Kentaro Nemoto', Takahiro Yagi', \\ Mitsuo Tsukamoto', Yoshihisa Fukushima', Tsuyoshi Ozawa', Ryu Shimada', Koichi Okamoto², Takeshi Tsuchiya', \\ Keijiro Nozawa ${ }^{1}$ and Keiji Matsuda'
}

\begin{abstract}
Background: Intussusception is a relatively common condition seen in children. In comparison, adult intussusception is rare and usually occurs as a complication in patients with organic diseases. It is responsible for $1 \%$ of all bowel obstructions, in most of intussusceptions a malignant tumor is involved. Herein, we present an extremely unusual case of intussusception that occurred as a complication at the site of a functional end-to-end anastomosis.

Case presentation: A 57-year-old female patient was diagnosed with tumors in the ascending and descending colon and was referred to our department. Laparoscopic hemicolectomy and laparoscopic descending colectomy were performed. The mechanical intestinal obstruction occurred on the 9th day postoperatively, and computed tomography scan revealed intussusception at the site of the ileocolic anastomosis. Endoscopic reduction was attempted, but the procedure was challenging. Surgery was then performed and revealed that the site of ileocolic anastomosis firmly adhered to the side wall and right retroperitoneum. However, the intestine in the oral side of the anastomosis was not fixed. Examination of the anastomotic site revealed that the ileum had passed through the anastomosis and prolapsed into the transverse colon. The ileocolic anastomosis was resected. End-to-end anastomosis was performed, and surgery was then completed. No neoplastic lesions were observed in the resected tissue of the lead point of intussusception. The postoperative clinical course was favorable, and the patient was discharged on the 11th day after the second round of surgery.
\end{abstract}

Conclusions: There are no reports the anastomosis is involved as part of the intussception, as observed in the present case. Intussusception should thus be considered as one of the causes of postoperative mechanical intestinal obstruction.

Keywords: Intussusception, Functional end-to-end anastomosis, Laparoscopic surgery

\section{Background}

Intussusception in adults is rare, and usually occurs as a complication in patients with organic diseases. We report a case of intussusception that occurred as a complication at the site of a functional end-to-end anastomosis.

\footnotetext{
* Correspondence: nijinsky14@yahoo.co.jp

${ }^{1}$ Department of Surgery, Teikyo University School of Medicine, 2-11-1 Kaga, Itabashi-ku, Tokyo 183-8605, Japan

Full list of author information is available at the end of the article
}

\section{Case presentation}

A 57-year-old female patient presented with a chief complaint of abnormal findings upon medical examination. She had no significant lifestyle/family history or medical history. Regarding her history of present illness, the patient was referred to our department after undergoing a computed tomography (CT) scan in September 2017, which revealed a tumor in the descending colon.

Hematological analysis revealed the following results: White blood cell count, $7900 / \mu \mathrm{l}$; hemoglobin level, 12.6 $\mathrm{g} / \mathrm{dL}$; platelet count, $28.4 \times 10^{4} / \mu \mathrm{l}$; carcinoembryonic 
antigen level, $3.3 \mathrm{ng} / \mathrm{mL}$; and CA 19-9 level, $11.1 \mathrm{U} / \mathrm{mL}$. The results were not significant.

Lower gastrointestinal endoscopy findings revealed a 25-mm type 0-Is lesion observed in the ascending colon and a $30-\mathrm{mm}$ type Is lesion in the descending colon. In the abdominal contrast-enhanced CT findings, the tumors could not be located, and lymph node, lung, or liver metastases were not observed. Regarding histopathological findings, biopsy results revealed that the tumor in the ascending colon was a high-grade adenoma and the tumor in the descending colon was a moderately differentiated adenocarcinoma. Endoscopic tumor resection was not possible due to the difficulty in maneuvering the endoscope in the ascending and descending colon. Thus, surgery was considered.

In the first round of surgery, surgery was initiated with five ports. No ascites, peritoneal dissemination, or liver metastases were observed. The ascending colon polyp was adenoma, but there was a polyp near the ileocecal valve. Therefore, it was difficult to resect the ascending colon and we chosed the right hemicolectomy. The descending colon polyp was adenocarcinoma on biopsy. However, we diagnosed intramucosal cancer and performed descending colon resection. Laparoscopic resection of the descending colon and right hemicolectomy was performed according to standard procedures. There were two functional end-to-end anastomoses. Regarding the clinical course after the first round of surgery, mechanical intestinal obstruction occurred on the 9th day postoperatively, and CT scan showed that intussusception occurred from the functional end-toend anastomosis (Figs. 1 and 2). An attempt at endoscopic reduction was unsuccessful (Fig. 3), and open surgery was considered on the 16th day after the first round of surgery.

In the second round of surgery, when midline laparotomy was performed, the site of the ileocolic anastomosis was found to be firmly adhered to the side wall and right retroperitoneum. Because the staple used for anastomosis may have adhered to the peritoneum. The intestines in the proximal side of the anastomosis were not fixed. Examination of the anastomosis revealed that the ileum had passed through the anastomosis and entered the transverse colon (Fig. 4). Although manual reduction was attempted, manipulation was challenging. The ileocolic anastomosis was resected. End-to-end anastomosis was performed, and surgery was completed. Histopathological findings revealed no lesions in the resected intussusceptum (Fig. 5). Regarding the clinical course after the second round of surgery, the postoperative clinical course was favorable, and the patient was discharged on the 10 th day after the second surgery.

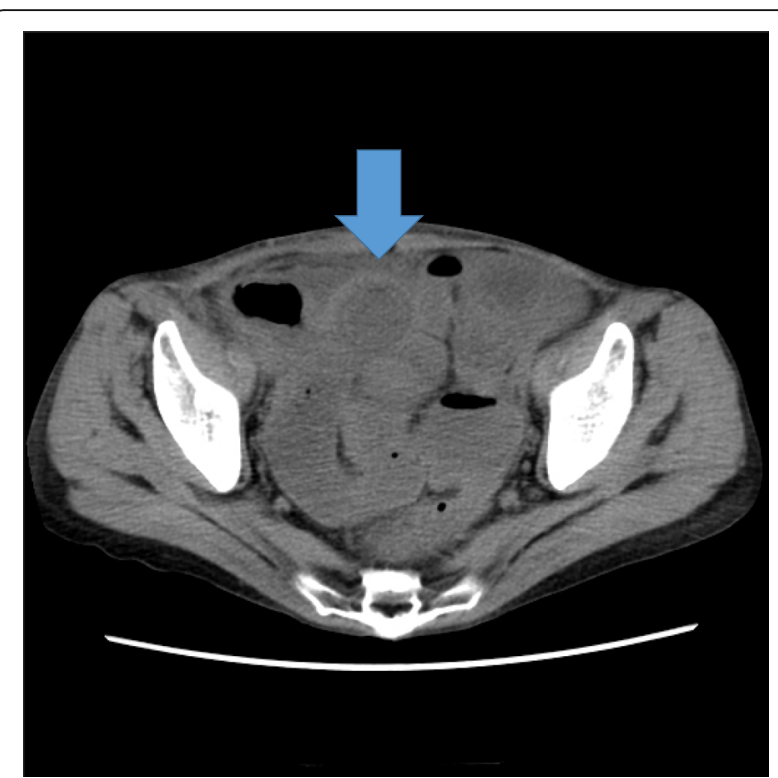

Fig. 1 Abdominal computed tomography scan. Intestinal fluids are accumulated in the small intestine, and the target sign can be observed (arrow)

\section{Discussion and conclusions}

Intussusception in adults is rare [1]. Over $90 \%$ of adult cases are associated with a specific etiology; approximately $19-42 \%$ are caused by malignant tumors, and $22-41 \%$ are attributed to benign tumors [2]. Approximately $90 \%$ of intussusception cases in adults are associated with organic diseases, and only $1-4 \%$ occur at the anastomotic site $[1,3,4]$. The pathogenetical mechanisms of postoperative intussusception are not wellunderstood due to its rarity. However, several hypotheses including prolonged postoperative ileus, extensive non-gentle handling and drying of intestines at primary surgery, postoperative radiation or chemotherapy have been proposed. [5] Although intestinal or abdominal adhesion is assumed to cause postoperative intussusception, mild intraperitoneal adhesion was observed in the present case.

Intussusception caused by functional end-to-end anastomosis is extremely rare. We searched the PubMed database for articles published between 1970 and December 2017 using "intussusception," "anastomosis," and "right hemicolectomy" as keywords. However, we did not find any relevant articles. "Intussusception" and "functional end-to-end Anastomosis" did not hit any human case reports.

The chief complaints only few symptoms that characterize the condition are observed, and the clinical course often varies [6]. Diagnosis of postoperative intussusception is difficult that ileus is a far more common postoperative morbidity, presenting with symptoms similar to obstruction, including nausea, vomiting, 

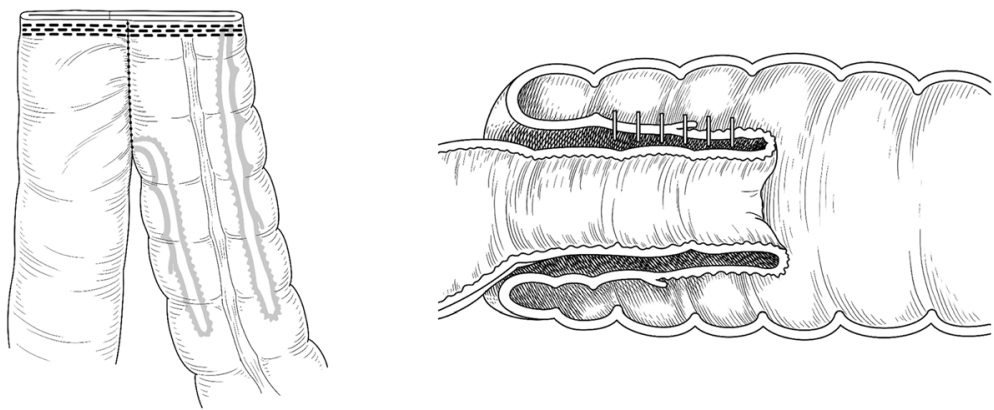

Fig. 2 Diagram showing differences anastomosis intussusception

abdominal distention, and obstipation. Further complicating the clinical picture in these patients is postoperative narcotics masking symptoms and reliable physical exams and the known negative effects of opiates on intestinal peristalsis. Postoperative ileus usually lasts on average 3 to 5 days, but can last much longer [7]. Therefore, it is challenging to establish a diagnosis based on only the clinical condition. However, there are characteristic findings that can be observed during diagnostic imaging. In abdominal ultrasonography, the donut sign, target sign, or multiple concentric ring sign, all of which are characteristic images, can be observed. In an abdominal CT scan, the multiple concentric ring sign, which comprises concentric circular repeats of high and low density layers, can be observed. These characteristic findings can easily facilitate the diagnosis via abdominal CT scan [8]. In the present case, the target sign was observed.

Intussusception is first treated with a barium enema or endoscopic reduction $[9,10]$. In the present case, although endoscopic reduction was attempted, the

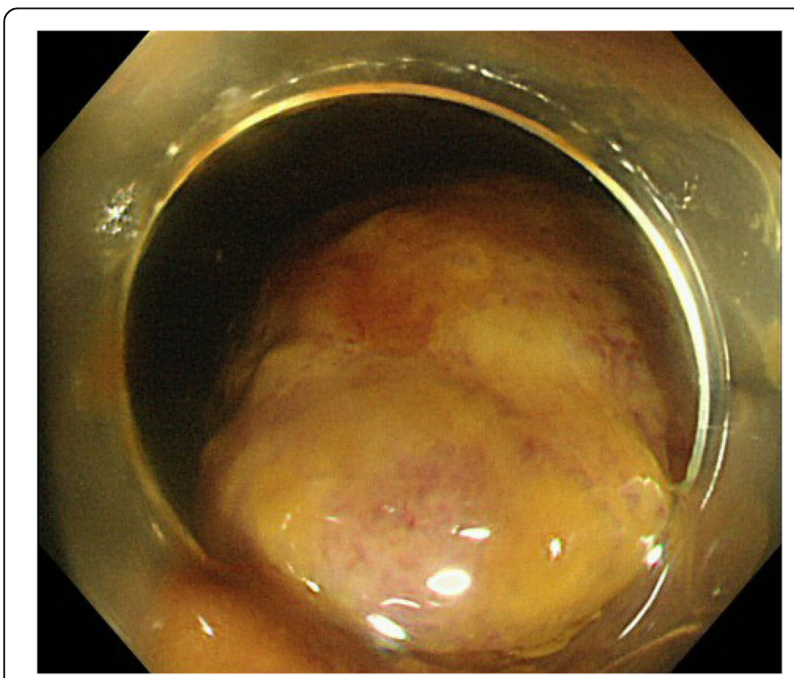

Fig. 3 Endoscopic image. Intussusception was observed, and the mucous membrane of the ileum was reddened procedure was challenging. In cases where endoscopic reduction is difficult, open surgery is then performed. When the intestine is mobile, as it is in cases with mobile cecum, surgical reduction procedures that do not involve intestinal resection but only reduction and fixation must be considered. Enterectomy should be performed if a tumor is suspected in the lead point of the intussusception.

Currently, idiopathic intussusception is believed to occur when a stimulus causes the circular muscle of the intestine to contract convulsively and enter the relaxed intestine that is contiguous to it in the anal side [11]. Elechi et al. have reported that a mobile cecum can be a causative factor of intussusception

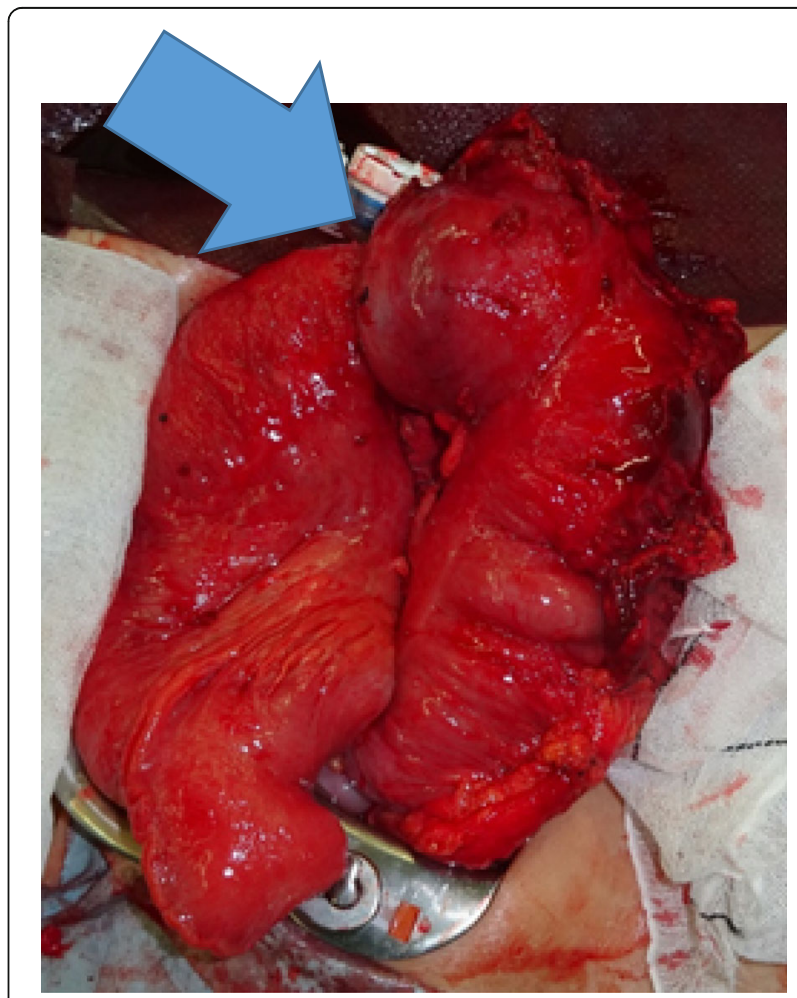

Fig. 4 Intraoperative image. Anastomosis is prolapsed in the direction of the arrow (transverse colon) 


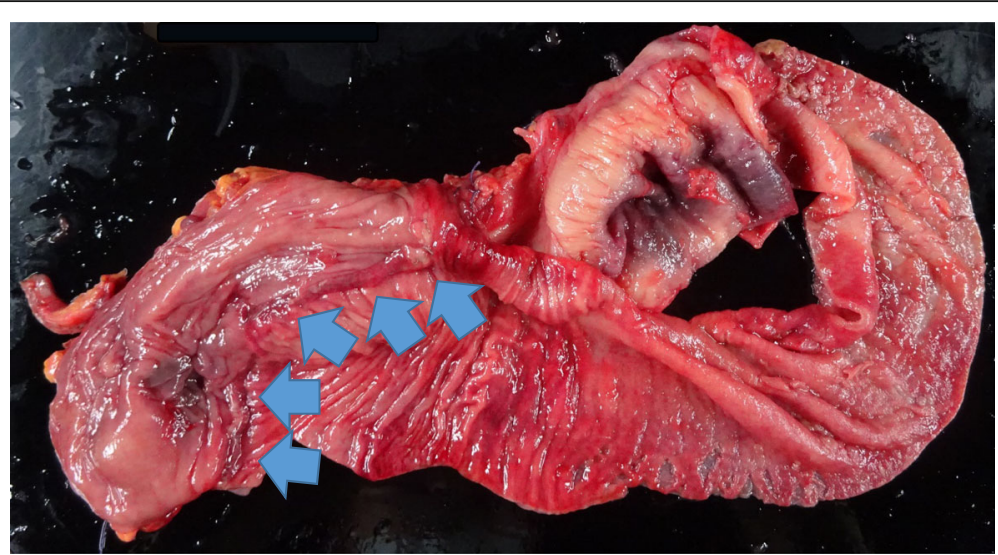

Fig. 5 Photograph of the specimen. Anastomosis is indicated with the arrow. The large intestine is on the left side, and the ileum is on the right side

[12]. If hemicolectomy is performed, as in the present case, then the site of anastomosis becomes mobile. Excessive peristalsis correlates with the onset of intussusception. Contractions in the left side of the colon can be classified as "short duration" (propagating at $4-6 \mathrm{~cm} / \mathrm{min}$ and lasting for $10 \mathrm{~s}$ ) or "long duration" (propagating at $0.5-2.0 \mathrm{~cm} / \mathrm{min}$ and lasting for approximately $1 \mathrm{~min}$ ) and are stimulated by physical factors such as the gastrocolic reflex. [3] However, the contractions in the right side of the colon differ from those in the left side, and they have the characteristics of mass peristalsis or vertical contraction. Mass peristalsis in the right side of the colon propagates at $12-180 \mathrm{~cm} / \mathrm{min}$ and lasts for $1 \mathrm{~min}$. The contractions in the right side are approximately two to three times stronger than those on the left side. Moreover, mass peristalsis in the right side of the colon can occur without requiring physical stimulation [3]. In other words, the right side of the colon has stronger peristalsis even in a physiological environment. In addition, its segments are longer, and there are relatively more cases in which it is mobile. Thus, it is relatively easy for intussusception to occur in that site (in comparison to other sites in the digestive tract). In the present case, although it was very difficult to identify the cause, it may be possible that the ileum advanced to the anal side and occured with intussusception because the peristalsis of the ileum is stronger than the colon. Relationship was not clear that intussusception occur as a complication owing to the location of the anastomosis in the right side of the colon and its high mobility, in addition to the peristaltic contractions in the right side.

As a surgery to prevent recurrence, there are methods to prevent invasion of the ileum into the colon by fixing the intestine to the abdominal wall, and to suppress recurrence by promoting postoperative adhesion [13-15]. We did not do it in this case, but we need to consider it.

Intussusceptions in adults are often caused by tumors, and they are rarely caused by other factors. To the best of our knowledge, no studies have reported cases of anastomosis as a cause of intussusception, as reported in the present case. Our case indicated that intussusception should be considered as one of the causes of postoperative mechanical intestinal obstruction.

\section{Abbreviation \\ $C T$ : computed tomography}

\section{Acknowledgements}

Not applicable.

\section{Authors' contributions}

$\mathrm{TH}$ made substantial contribution to conception, conducted a literature search and drafted the manuscript. TH, YH and TY made the contribution for acquisition of data. TH, KM, RS and MT performed the operation. TH, YH, KN, $\Pi$, KO, KN, YF, TO, YO, TY and KO reviewed the manuscript and gave final approval for publication. All authors read and approved the final manuscript.

\section{Funding}

None.

Availability of data and materials

All available data supporting our findings are listed in the tables which are shown in the manuscript. Thus, our conclusions can be ascertained from the published data.

\section{Ethics approval and consent to participate}

All procedures performed in studies involving human participants were in accordance with the ethical standards of the institutional and/or national research committee and with the 1964 Helsinki declaration and its later amendments or comparable ethical standards.

It is approved by the ethics committee of Teikyo University (approval date, 23 August 2016, registration number; 16-032).

\section{Consent for publication}

I got written informed consent from the patient for publication of this case report.

Competing interests

The authors declare that they have no competing interests. 


\section{Author details}

'Department of Surgery, Teikyo University School of Medicine, 2-11-1 Kaga, Itabashi-ku, Tokyo 183-8605, Japan. ${ }^{2}$ Department of Surgery, National

Defense Medical College, Tokorozawa, Japan.

Received: 8 February 2019 Accepted: 20 June 2019

Published online: 02 July 2019

\section{References}

1. Zubaidi A, Al-Saif F, Silverman R. Adult intussusception: a retrospective review. Dis Colon Rectum. 2006 Oct:49(10):1546-51.

2. Smith MA, Dent DM, Botha JB. Intussusception in adults. S Afr J Surg. 1978 Jun;16(2):139-43.

3. Stein JH. Internal medicine, Stein. Fifth edition. St. Louis, Missouri: Mosby Inc: 1998. p. 1976-80.

4. Azar T, Berger DL. Adult intussusception. Ann Surg. 1997 Aug;226(2):134-8.

5. gachabavov M. Postoperative spontaneous intussusception caused by a Jejunal peritoneal cyst: a case report and literature review. Bull Emerq Trauma. 2017:5(2):132-4.

6. Ikeda T, Koshinaga T, Inoue M, Goto H, Sugitou K, Hagiwara N. Intussusception in children of school age. Pediatr Int. 2007 Feb;49(1):58-63.

7. Ahmad SH, Rajalakshmi W, Harry TP, et al. Small bowel intussusception causing a postoperative bowel obstruction following laparoscopic low anterior resection in an adult. Proc (Bayl Univ Med Cent). 2014;27(2):128-30.

8. Masuda H, Hayashi S, Nakamura Y, Horiuchi H, Watanabe K, Hayashi I, et al. Intussusception in adult. Nihon Univ J Med. 1992:34:179-89.

9. Thorsteinsson M, Burgdorf SK, Penninga L. Intussusception in an adult with cystic fibrosis successfully reduced with contrast enema. BMJ Case Rep. $2015 \mathrm{Jul}$.

10. Applegate KE. Intussusception in children: evidence-based diagnosis and treatment. Pediatr Radiol. 2009 Apr;39(Suppl 2):140-3.

11. Reymond RD. The mechanism of intussusception: a theoretical analysis of phenomenon. Br J Radiol. 1972; Jan;45(529):1-7.

12. Elechi EN, Elechi GN. Intussusception: is floating caecum a causative factor? Analysis of 10 cases. East Afr Med J. 1990 Nov;67(11):779-84.

13. Niramis R, Watanatittan $S$, Kruatrachue A, et al. Management of recurrent intussusception: nonoperative or operative reduction? J Pediatr Surg. 2010;45:2175-80

14. Burrington JD. Surgical technique for the prevention of recurrent intussusception in childhood. Surg Gynecol Obstret. 1980;150:572-3.

15. Chang YT, Lee JY, Wang JY, et al. Early laparoscopy for ileocolic intussusception with multiple recurrence in children. Surg Endosc. 2009;23:2001-4.

\section{Publisher's Note}

Springer Nature remains neutral with regard to jurisdictional claims in published maps and institutional affiliations.

\section{Ready to submit your research? Choose BMC and benefit from:}

- fast, convenient online submission

- thorough peer review by experienced researchers in your field

- rapid publication on acceptance

- support for research data, including large and complex data types

- gold Open Access which fosters wider collaboration and increased citations

- maximum visibility for your research: over $100 \mathrm{M}$ website views per year

At BMC, research is always in progress.

Learn more biomedcentral.com/submissions 